\title{
Editorial
}

\section{Editorial Review}

With this issue of College \& Research Libraries, the current editorial staff, board, and cadre of referees begin their second, and final, three-year term of service. During our first term, 2008 to 2011, we brought you five or six articles and an equal number of book reviews every other month. We hope you as readers found them enlightening on a wide variety of academic library topics. We culled the many manuscripts we received for consideration to select, through the peer review process, the best research and writing submitted. Our acceptance statistics with manuscripts are fairly consistent year to year: we receive about one hundred manuscripts for consideration and from these we select thirty for publication.

My experience as editor of our journal for the last three years has only reinforced my commitment to the blind peer review process we follow in selecting manuscripts for publication. Our review process, similar to that of other peer review scholarly journals, works like this: step one, manuscript (without author information) screened by an editorial assistant for worthiness of peer review; step two, manuscript (without author information) reviewed by two or more referees; and step three, editor makes final decision based on peer reviews and own evaluation. This process takes two to three months to complete. While no process like this is perfect, peer review, in my opinion, comes close in its unbiased and careful critique of writing and research results. Usually there is consensus among the referees and the editor in our first rounds of evaluation; when there is not, I seek more independent reviews until I see a clear pattern of evaluation emerge.

Any credit for the value of our journal must, of course, go first to the authors of our articles. It is their insights, found through their research and expressed in their good writing, that make our journal worthwhile. We appreciate the time, effort, concentration, creativity, and persistence demanded of our authors. Most of our manuscripts go through one or more revisions before being finally accepted for publication.

Our referees deserve a great deal of credit too. We have a cadre of ninety experienced academic librarian writers and researchers with their own excellent publication records who volunteer their time to act as impartial evaluators of our manuscript submissions. Referees are the anonymous, unsung heroes of the scholarly communications process. I am continually impressed by the quality of their rigorous reviews and their thoughtful and constructive comments and judgments. As much as possible I try to share referee evaluations with authors, so they can revise accepted manuscripts to make them even better or to rewrite their papers to eliminate more serious weaknesses. Authors should understand that most scholarly journals like ours reject more manuscripts that they accept. Critical but constructive feedback from the peer review process should be used to improve future writing efforts, not discourage them.

The editorial team for our journal consists of the editor, editorial administrator who keeps all our processes in order, the editorial assistants, the book review editor, and the editorial board. All our names appear on the journal's masthead. Also, staff in the ACRL Office handles essential activities of copy editing, journal production, and business operations for the journal. Our basic job is to support our 
authors, book reviewers, and referees in their creative and evaluative work.

Over the last three years our editorial team and ACRL have made several significant improvements to College $\mathcal{E}$ Research Libraries. With ACRL support, we moved our journal's manuscript submission and peer review processes from a manual operation to an online system called "Editorial Manager" from Aries Systems. This system has been adopted by many scholarly societies for their publications and has certainly streamlined and quickened the internal processes of our journal. In 2008, we introduced an online prepublication service that allows us to make manuscripts publicly available shortly after their acceptance, thus eliminating a nine month to one year blackout before their formal print and online publication. And finally, with just the last issue of the journal, we have made College $\mathcal{E}$ Research Libraries a fully open access journal. Our editorial team and many members of ACRL campaigned for this change to make our journal a model of best practice in scholarly communications.

Joseph Branin, Editor 